\title{
Membrane-Bound Serine Protease Inhibitor HAI-1 Is Required for Maintenance of Intestinal Epithelial Integrity
}

\author{
Makiko Kawaguchi, ${ }^{*}$ Naoki Takeda, ${ }^{\dagger}$ \\ Shinri Hoshiko, ${ }^{*}$ Kenji Yorita, ${ }^{*}$ Takashi Baba, ${ }^{*}$ \\ Akira Sawaguchi, ${ }^{\ddagger}$ Yuriko Nezu, ${ }^{\S}$ \\ Tsutomu Yoshikawa, "Tsuyoshi Fukushima, ${ }^{*}$ and \\ Hiroaki Kataoka* \begin{abstract}
Department of Pathology and the Department of Anatomy, ${ }^{\neq}$ Faculty of Medicine, University of Miyazaki, Miyazaki; the Center for Animal Resources and Development ${ }^{\dagger}$ Institute of Resource Development and Analysis, Kumamoto University, Kumamoto; the Advanced Medical Research Laboratory, ${ }^{\lessgtr}$ Target Discovery and Biomarker Research Department, Yokohama; and the Biologics Research Department, "Mitsubishi Tanabe Pharma, Osaka, Japan
\end{abstract} \\ From the Section of Oncopathology and Regenerative Biology, *
}

Hepatocyte growth factor activator inhibitor type 1 (HAI-1), encoded by the serine protease inhibitor Kunitz type 1 (SPINT1) gene, is a membrane-bound serine protease inhibitor expressed in epithelial tissues. Mutant mouse models revealed that HAI-1/SPINT1 is essential for placental labyrinth formation and is critically involved in regulating epidermal keratinization through interaction with its cognate cell surface protease, matriptase. HAI-1/SPINT1 is abundantly expressed in both human and mouse intestinal epithelium; therefore, we analyzed its role in intestinal function using mice with intestinal epithelial cell-specific deletion of Spint1 generated by interbreeding mice carrying Spint $^{\text {LoxP }}$ homozygous alleles with transgenic mice carrying the Cre recombinase gene controlled by the intestine-specific Villin promoter. Although the resulting mice had normal development and appearance, crypts in the proximal aspect of the colon, including the cecum, exhibited histologic abnormalities and increased apoptosis and epithelial cell turnover accompanied by increased intestinal permeability. Distended endoplasmic reticula were observed ultrastructurally in some crypt epithelial cells, indicative of endoplasmic reticular stress. To study the role of HAI-1/SPINT1 in mucosal injury, we induced colitis by adding dextran sodium sulfate to the drinking water. After dextran sodium sul- fate treatment, intestine-specific HAI-1/SPINT1-deficient mice had more severe symptoms and a significantly lower survival rate relative to control mice. These results suggest that HAI-1/SPINT1 plays an important role in maintaining colonic epithelium integrity. (AmJ Pathol 2011, 179:1815-1826; DOI: 10.1016/j.ajpath.2011.06.038)

Hepatocyte growth factor activator inhibitor type 1 ( $\mathrm{HAl}-1)$ is a Kunitz-type serine protease inhibitor encoded by the SPINT1 (serine protease inhibitor, Kunitz type 1) gene. ${ }^{1-3}$ It is synthesized as a type 1 transmembrane protein having two extracellular Kunitz-type serine protease inhibitor domains, a transmembrane domain and a short intracytoplasmic domain. The two Kunitz domains are separated by a low-density lipoprotein receptor-like domain. In humans, HAI-1/SPINT1 is expressed in most epithelial tissues, with the most abundant expression in the gastrointestinal tract and placental cytotrophoblasts, and its subcellular localization is predominantly basolateral in polarized epithelial cells. ${ }^{4,5}$ The mouse HAI-1/ SPINT1 also shows expression patterns that are similar to those in humans. ${ }^{6}$ Because of this similarity, the biological functions of HAI-1/SPINT1 in vivo have been studied in mice using Spint1 mutant mice. ${ }^{6-9}$

To date, several serine proteases have been proposed as targets for HAI-1/SPINT1, including hepatocyte growth factor activator (HGFAC), kallikrein 1-related peptidase 4, kallikrein 1-related peptidase 5, matriptase (also known as epithin, MT-SP1, ST14, and PRSS14), hepsin (TMPRSS1), TMPRSS13, and prostasin (PRSS8). 2,3,10-12 Matriptase, hepsin, and TMPRSS13 belong to the type 2 transmembrane serine protease superfamily, whereas prostasin is a glycosylphosphatidylinositol-anchored protein. ${ }^{12}$ These target proteases are known to participate in

Supported by grants-in-aid for scientific research (B) no. 20390114 from the Ministry of Education, Science, Sports and Culture, Japan.

Accepted for publication June 27, 2011.

Address reprint requests to Hiroaki Kataoka, M.D., Ph.D., Section of Oncopathology and Regenerative Biology, Department of Pathology, Faculty of Medicine, University of Miyazaki, 5200 Kihara, Kiyotake, Miyazaki 889-1692, Japan. E-mail: mejina@med.miyazaki-u.ac.jp. 
bioactive molecule processing. For example, matriptase activates hepatocyte growth factor (HGF), macrophagestimulating protein (MSP), protease-activated receptor 2, and urokinase-type plasminogen activator in the pericellular microenvironment and also activates other membrane-bound proteases, such as prostasin, which is an important activator of epithelial sodium channels. ${ }^{12}$ Consequently, the interaction between HAI-1/SPINT1 and matriptase is critical for tissue morphogenesis and cellular biology. In fact, mice lacking HAI-1/SPINT1 have completely impaired placental labyrinth layer development, and the concomitant deletion of the matriptase/St14 gene rescues this phenotype. ${ }^{6,7}$ In mouse skin, HAI-1/SPINT1 interacts with matriptase to play a central role in regulated keratinization of the epidermis. ${ }^{8,9}$ The participation of HAI-1/SPINT1 in the maintenance of epidermal integrity in zebrafish was also demonstrated. ${ }^{13}$ Even in neoplastic cells, short hairpin RNA knockdown of HAl-1/ SPINT1 induced epithelial to mesenchymal transition in certain human epithelial cancer cell lines with enhanced metastatic colonization capability. ${ }^{14,15}$ These lines of evidence strongly suggest that HAI-1/SPINT1 has a significant functional role in epithelial biology.

The intestinal epithelium provides an important barrier against luminal contents, such as microorganisms, food products, and digestive enzymes. Disruption of epithelial barrier functions confers susceptibility to colitis. ${ }^{16}$ Although HAI-1/SPINT1 is strongly expressed by intestinal epithelial cells, its function in the intestinal epithelium is not known. On the other hand, a recent study showed that matriptase, one of the most important target proteases of HAI-1/SPINT1, is critical for maintaining epithelial integrity ${ }^{17}$; thus, $\mathrm{HAl}-1 /$ SPINT1 may also have an important role in sustaining intestinal epithelium integrity. Because ablation of the Spint1 gene in mice results in embryonic lethality due to impaired placental development, we rescued placental development in HAI-1/SPINT1 knockout mice to study the functions of HAI-1/SPINT1 in viable mice. ${ }^{8}$ However, although HAl-1/ SPINT1-deficient mice were delivered after placental rescue, they showed significant skin abnormalities and died within 15 days of birth, which prevented further analysis of intestinal tissues. ${ }^{8}$ In the present study, we attempted to generate mice with intestinal tissue-specific conditional ablation of the Spint1 gene to overcome the lethality observed in HAl-1/ SPINT1-null mice and to analyze its function in intestinal tissue. We found morphologic abnormalities in the colonic epithelium with enhanced epithelial cell apoptosis and increased mucosal permeability. Moreover, mice lacking intestinal HAl-1/ SPINT1 showed significantly enhanced susceptibility to colitis induced by dextran sodium sulfate (DSS) exposure.

\section{Materials and Methods}

\section{Antibodies}

The following antibodies were used: anti-mouse HAI-1 goat polyclonal IgG (R\&D Systems, Minneapolis, MN), anti-5-bromo-2-deoxyuridine (BrdU) mouse monoclonal IgG (Clone BU-33; Sigma-Aldrich, St. Louis, MO), anticleaved caspase-3 (Asp175) rabbit polyclonal IgG (Cell
Signaling Technology, Boston, MA), anti-phosphorylated c-Jun N-terminal kinase/stress activated protein kinase (JNK/SAPK) (Thr183/Thr185) rabbit polyclonal IgG (Cell Signaling Technology), anti-growth arrest and DNA damage inducible 153 (GADD153) rabbit polyclonal IgG (F168; Santa Cruz Biotechnology, California, CA), antimouse clusterin goat polyclonal IgG (R\&D Systems), antimatriptase rabbit polyclonal IgG (AnaSpec, San Jose, CA); anti-ZO-1 rabbit polyclonal antibody (Life Technologies Japan, Tokyo, Japan); and anti-occludin rabbit polyclonal IgG (Life Technologies Japan).

\section{Generation of HAI-1/SPINT1 Conditional Knockout Mice}

All of the animal work was performed using protocols approved by University of Miyazaki Animal Research Committee, in accordance with international guidelines for biomedical research involving animals. The mouse Spint1 gene was cloned from a mouse (129/SVJ) genomic bacterial artificial chromosome library, and two DNA fragments digested with $\mathrm{BamHI}$ were found to cover the entire mouse Spint 1 gene, as described previously. ${ }^{6}$ These clones were subcloned into a pBluescript II SK+ phagemid vector (Agilent Technologies, Palo Alto, CA) and used to construct a targeting vector. LoxP sites were inserted into intron 3 and exon 11, and a neomycin resistance gene cassette for positive selection was also inserted within exon 11 and was flanked by a loxP site. In addition, the targeting vector contained a diphtheria toxin expression cassette for negative selection. An EcoRI site was inserted to screen for the targeting vector by Southern blotting. The targeting vector was linearized with Sacll and transfected into C57BL/6 strain embryonic stem cells by electroporation. Correctly targeted embryonic stem clones were selected using G418 and identified by Southern blotting. Two independently targeted clones were microinjected into morulae of ICR mice, and the resulting chimeras were mated with $\mathrm{C} 57 \mathrm{BL} / 6$ mice. Germline transmission of the targeted allele was detected by progeny coat color and Southern blotting. Heterozygous offspring were crossed to produce homozygous mutant offspring. Homozygous floxed Spint1 mice (Spint ${ }^{\text {LoxP/LoxP }}$ ) were crossed with mice harboring the Cre recombinase under control of the intestine-specific villin promoter $\left(\right.$ Villin-Cre ${ }^{+/ 0}$ ) obtained from Jackson Laboratories (Bar Harbor, ME). The offspring carrying a floxed Spint1 allele and Villin-Cre were again bred to obtain homozygous floxed Spint1 mice with intestine-specific expression of Cre recombinase (Spint $1^{\text {LoxP/LoxP Nillin-Cre }}{ }^{+/ 0}$ ).

\section{Induction of Experimental Colitis}

For colitis induction, Spint $1^{\text {LOXP/LoxP } / \text { Villin-Cre }}{ }^{+/ 0}$ mice and their littermate control floxed mice lacking Cre expression (Spint 1 LoxP/LOXP/Villin-Cre ${ }^{0}$ ) were treated with DSS (molecular weight, 36-50 kDa; MP Biomedicals, Solon, $\mathrm{OH}$ ) in the drinking water. To assess the recovery after very mild colitis, mice were treated with $1 \%$ DSS for 4 days, and then the drinking water was changed to distilled water 
without DSS for the next 7 days. For the acute, severe colitis model, mice were treated with $2.5 \%$ DSS for 7 days, and then the drinking water was changed to distilled water without DSS. Mice were weighed daily and visually inspected for rectal bleeding and diarrhea.

\section{Intestinal Permeability Assay}

To assess intestinal barrier function, an intestinal permeability assay was performed. ${ }^{17}$ Briefly, $250 \mu \mathrm{g} / \mathrm{g}$ body weight of fluorescein isothiocyanate (FITC)-dextran (4 kDa; Sigma-Aldrich) was administrated by gavage to $12-$ week-old Spint1 ${ }^{\text {LoxP/LoxP/Nillin-Cre }}{ }^{+/ 0}$ and control

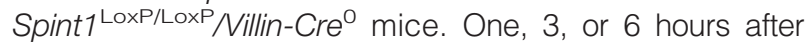
administration of FITC-dextran, the blood samples were obtained from the right ventricle, and EDTA-containing plasma samples were collected by centrifugation at $960 \times g$ for 20 minutes at $4^{\circ} \mathrm{C}$. A total of $75 \mu \mathrm{L}$ of plasma was diluted in 250 $\mu \mathrm{L}$ of PBS, and fluorescence was quantified using a fluorometer (DTX800 Multimode Detector; Beckman Coulter, Fullerton, CA) with excitation an emission wavelengths of $485 \mathrm{~nm}$ and $535 \mathrm{~nm}$, respectively. FITC-dextran concentrations were determined from standard curves generated by serial dilution of FITC-dextran. In another experiment, mice were treated with FITC-dextran as described above followed by preparation of small and large intestine cryosections for fluorescence microscopy.

\section{RT-PCR and Real-Time RT-PCR}

Total RNA was prepared with TRIzol (Life Technologies Japan) followed by DNase I (Takara Bio, Shiga, Japan) treatment. For RT-PCR, $3 \mu \mathrm{g}$ of total RNA was reversetranscribed with a mixture of Oligo (dT)12-18 (Life Technologies Japan) and random primers (hexamers) (Takara Bio) using 200 units of ReverTra Ace (Toyobo, Osaka, Japan), and $1 / 30$ of the resulting cDNA was processed for each PCR reaction with $0.2 \mu \mathrm{mol} / \mathrm{L}$ of both forward and reverse primers and AmpliTaq Gold PCR Master Mix (Life Technologies Japan). The primer sequences used are described in Table 1. For quantitative real-time RT-PCR using cyber green, PCR was performed in a LightCycler (Roche Diagnostics Japan, Tokyo, Japan) as previously described. ${ }^{14}$ For internal control, $\beta$-actin mRNA was also measured.

\section{Histologic, Immunohistochemical, and Immunofluorescent Analyses}

Intestinal tissues were fixed overnight in 4\% paraformaldehyde in PBS and then dehydrated and embedded in paraffin. Sections $4 \mu \mathrm{m}$ thick were prepared and stained with H\&E or PAS stain. To count shedding epithelial cells in the proximal aspect of the colon, H\&E-stained mucosal tissue was randomly photographed at $\times 400$ magnification. Then the shedding epithelial cells per field were counted by two independent investigators. For immunohistochemistry and immunofluorescence, the sections were processed for antigen retrieval by microwave in 10 $\mathrm{mmol} / \mathrm{L}$ citrate buffer $\left(\mathrm{pH}\right.$ 6.0) for 10 minutes at $96^{\circ} \mathrm{C}$ (phospho-JNK/SAPK, cleaved caspase-3, GADD153, matriptase) and autoclaved in $10 \mathrm{mmol} / \mathrm{L}$ citrate buffer ( $\mathrm{pH}$ 6.0) for 10 minutes (BrdU) or protease K (Dako Japan, Tokyo, Japan) for 10 minutes at room temperature (HAI-1/SPINT1, ZO-1, occludin). The sections were treated with $3 \% \mathrm{H}_{2} \mathrm{O}_{2}$ in PBS for 10 minutes for immunohistochemistry. After blocking in solution recommended by the supplier of each antibody for 1 hour at room temperature, the sections were incubated with primary antibodies according to the instruction by the supplier of each antibody and processed as previously described. ${ }^{6,8}$ For immunohistochemistry, sections were incubated with Envision-labeled polymer reagents (Dako) for 30 minutes at room temperature. Reactions were revealed using nickel and cobalt-3,3'-diaminobenzidine (Pierce, Rockford, IL) and counterstained with Mayer's hematoxylin. For immunofluorescence, the sections were incubated for 30 minutes at room temperature with Alexa Fluor 488-conjugated goat anti-rabbit IgG (Life Technologies Japan). The sections were investigated with an Axio Imager A2 (Carl Zeiss Microlmaging, Tokyo, Japan). The primary antibody was omitted for negative controls in both immunohistochemical and immunofluorescence analyses.

Table 1. Primer Sequences for RT-PCR and Real-Time RT-PCR

\begin{tabular}{|c|c|c|c|}
\hline Target & Forward & Reverse & Product size, bp \\
\hline HGFAC & $5^{\prime}-\mathrm{TGACACAGACATTTGGCATTGAGA-3^{ \prime }}$ & 5'-GCAGGCAGATGGGTTGAACA-3' & 150 \\
\hline Matriptase & $5^{\prime}$-CACGAATGATGTGTGTGGGTTTC-3' & 5'-CCTGGAACATTCGCCCATCT-3' & 105 \\
\hline Hepsin & $5^{\prime}$-TGCCTTGGTCCACCTCTCTAGCTC-3' & 5' - CGGGGCTGTTGCAAACTTCGTTGC-3' & 202 \\
\hline TMPRSS2 & $5^{\prime}-$ TCCAGGGGTCTGTCGACTCTTG-3' & $5^{\prime}$-ACCGTCACGTTCCCGTATACTCC-3' & 147 \\
\hline TMPRSS4 & 5'-TACTGCAGGCATCAGTCCAGGTC-3' & $5^{\prime}-$ TGGTACATCAAAGGCCCACCAC- $3^{\prime}$ & 153 \\
\hline TMPRSS13 & 5'-ATGATGTGTGCCGGGGATCTACG-3' & 5' - TCCGGAATCGTACCTCACTCTCC-3' & 216 \\
\hline Prostasin & 5'-AGCCCTCTTCTCGGTAGCTTGAG-3' & $5^{\prime}$-TGGTGTCTGCTGCTCACTGCTTC-3' & 152 \\
\hline $\mathrm{HAl}-2$ & 5'-TCGCCTTGGTAGCTTCGCTG-3' & $5^{\prime}$-GTGACGGCCTTCGGGACACA-3' & 205 \\
\hline $\mathrm{HAl}-1$ & 5'-GCTGTGCCCGATTCACCTATG-3' & $5^{\prime}$-GACCACTATGATGCAGATGACCAGA-3' & 194 \\
\hline$\beta$-Actin & 5'-TGACAGGATGCAGAAGGAGA-3' & 5'-GCTGGAAGGTGGACAGTGAG-3' & 131 \\
\hline $\mathrm{Bcl}-2$ & 5'-ACCGTCGTGACTTCGCAGAG-3' & 5'-GGTGTGCAGATGCCGGTTCA-3' & 238 \\
\hline $\mathrm{Bcl}-\mathrm{XL}$ & $5^{\prime}-$ ATCAATGGCAACCCATCCTGG- $3^{\prime}$ & 5'-TTGTCTACGCTTTCCACGCAC-3' & 319 \\
\hline Bax & $5^{\prime}$-CGGCGAATTGGAGATGAACTG-3' & 5' - GCAAAGTAGAAGAGGGCAACC-3' & 160 \\
\hline Bad & $5^{\prime}$-GCCCTAGGCTTGAGGAAGTC-3' & 5' - CAAACTCTGGGATCTGGAACA-3' & 108 \\
\hline IL $-1 \beta$ & $5^{\prime}$-GTAATGAAAGACGGCACACCC-3' & 5' -GTGCTGATGTACCAGTTGGG-3' & 157 \\
\hline IL-6 & $5^{\prime}$-AGCCAGAGTCCTTCAGAGAG-3' & $5^{\prime}$-ACTCCTTCTGTGACTCCAGC-3' & 136 \\
\hline IL-10 & 5' -ATGCAGGACTTTAAGGGTTACTTGGGTT-3' & 5' - ATTTCGGAGAGAGGTACAAACGAGGTTT-3' & 454 \\
\hline TLR-2 & $5^{\prime}-$ AGCAGCTGGAGAACTCTGACCC-3' & $5^{\prime}$-AGTTCGTACTTGCACCACTCGC-3' & 164 \\
\hline TLR-4 & $5^{\prime}$-TTCTGAGCAGCCGCTCTGGCATCATC-3' & 5'-CTCTGCTGTTTGCTCAGGATTCGAGGC-3' & 208 \\
\hline
\end{tabular}




\section{BrdU Labeling}

Ten-week-old mice were injected i.p. with BrdU (50 $\mu \mathrm{g} / \mathrm{g}$ of body weight; Sigma-Aldrich), were sacrificed 1.5 hours after injection, and had their intestines removed for immunohistochemical analysis. Formalin-fixed, paraffin-embedded sections were processed for antigen retrieval and immunohistochemical staining using anti-BrdU antibody as described above. The ratio of nuclear BrdU-positive cells to total crypt cells was counted by two independent investigators.

\section{In Situ Hybridization}

For in situ hybridization of matriptase mRNA, the cDNA of matriptase was generated by RT-PCR and subcloned into the TOPO TA cloning vector (Life Technologies Japan). In vitro transcription to generate digoxigenin-labeled RNA probes was performed according to the manufacturer's instructions (Roche Diagnostics Japan). The same amount of each antisense or sense probe was used for hybridization, with the sense probe used as a negative control. The in situ hybridization reaction was performed using a fully automated in situ hybridization apparatus (Ventana HX System Discovery and RiboMap System; Roche Diagnostics Japan), according to the manufacturer's instructions. Hybridization was performed by using $200 \mathrm{ng}$ per slide of digoxigenin-labeled RNA probe at $65^{\circ} \mathrm{C}$ for 6 hours. After hybridization, signals were detected by alkaline phosphatase-conjugated antidigoxigenin antibody. The reaction was detected with a

A

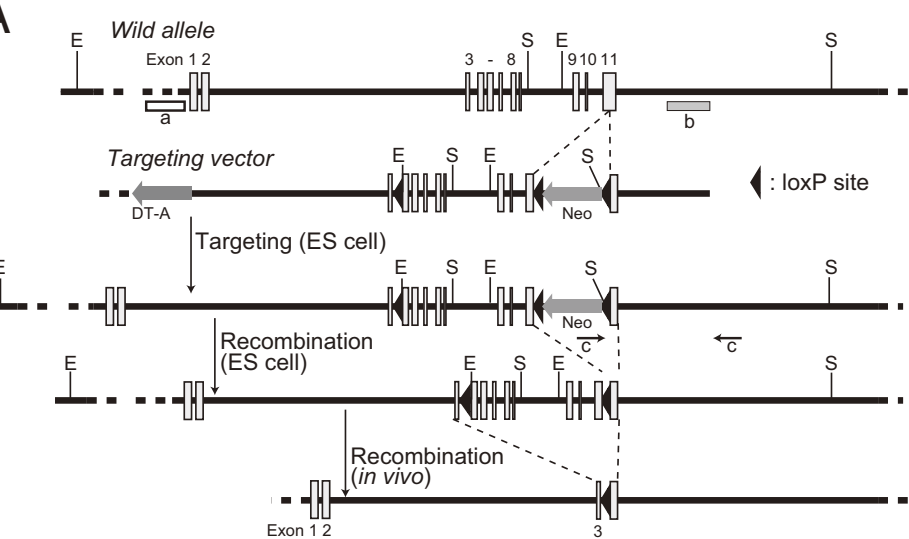

B

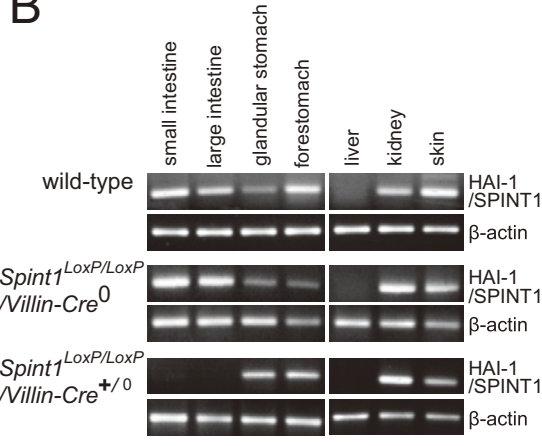

C
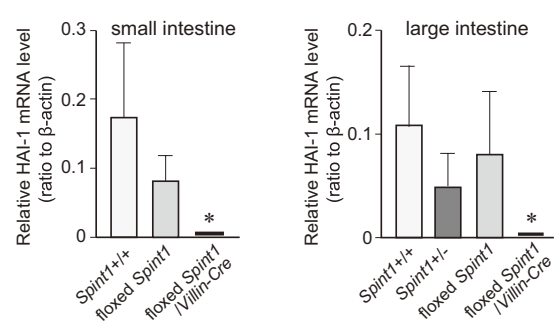

D

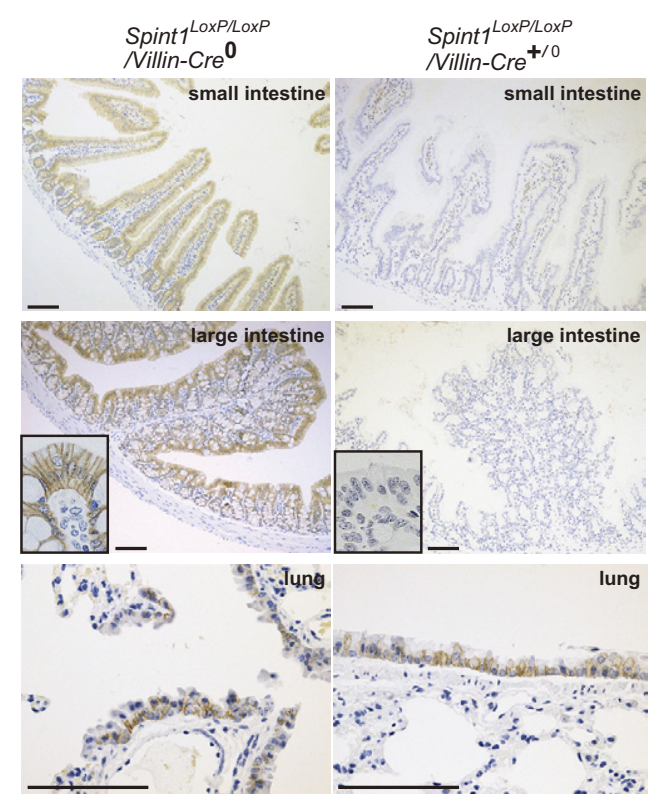

Figure 1. Generation of intestine-specific conditional Spint1 knockout mice. A: Schematic drawing of the Spint1 gene, targeting vector, floxed Spint1 gene, and floxed Spint1 gene after Cre-mediated recombination. The recombination eventually leads to the excision of exons 4 to 10 and part of exon 11 , which was previously shown to generate a null allele ${ }^{6} \mathbf{a}$ and $\mathbf{b}$ : Southern probe; c: PCR primer position. E, EcoRI site; S, SpeI site. B: RT-PCR analysis for HAI-1/SPINT1 mRNA expression in wild-type, Spint $1^{\text {LoxP/LoxP }} /$ Villin-Cre $^{0}$, and Spint ${ }^{\text {LoxP/LoxP } / \text { Villin-Cre }}{ }^{+/ 0}$ mice. The expression of HAI-1/SPINT1 is absent in the intestinal tissue of Spint1 ${ }_{\text {LoxP/LoxP } / \text { Villin-Cre }}^{+/ 0}$ mice. C: Quantitative real-time RT-PCR to determine intestinal HAI-1/SPINT1 mRNA levels in wild-type (Spint1 ${ }^{+/+}$), heterozygous $\left(\right.$ Spint $^{+/-}$), Spint1 ${ }^{\text {LoxP/LoxP }} /$ Villin-Cre ${ }^{0}$ (floxed Spint1), and Spint1 ${ }^{\text {LoxP/LoxP } / \text { Villin-Cre }}{ }^{+/ 0}$ (floxed Spint1/Villin-Cre) mice. Values are the mean \pm SD of four experiments. *Undetectable. D: Immunohistochemical detection of HAI-1/SPINT1 in mice showing successful deletion of Spint1 gene in the small and large intestinal epithelium but not in the lung bronchiolar epithelium. Inset: High magnification showing basolateral localization of HAI-1/SPINT1 in the colonic epithelium from control mice but not in that from Spint $1^{\text {LoxP } / \text { LoxP }} /$ Villin-Cre ${ }^{+/ 0}$ mice. Scale bar $=100 \mu$ m. E: RT-PCR study of HGFAC, membrane-bound serine protease expression (matriptase, hepsin, Tmprss2, Tmprss4, Tmprss13, prostasin), HAI-2/SPINT2, and HAI-1/SPINT1 in different intestine sections from littermate control (Spint1 $\left.{ }^{\text {LoxP/LoxP } / \text { Villin-Cre }}{ }^{O}\right)$ and intestine-specific HAI-1/SPINT1-deficient $\left(\right.$ Spint1 ${ }^{\text {LoxP/LoxP }} /$ Villin-Cre $\left.^{+/ 0}\right) \mathrm{mice}^{-}$ 
BlueMap kit (Roche Diagnostics Japan) and counterstained with nuclear fast red.

\section{Transmission Electron Microscopy}

Specimens were fixed with a mixture of $2 \%$ paraformaldehyde and $2.5 \%$ glutaraldehyde in $0.1 \mathrm{~mol} / \mathrm{L}$ phosphate buffer, pH 7.4. After rinsing with the buffer, the specimens were postfixed with $1 \%$ osmium tetroxide in $0.1 \mathrm{~mol} / \mathrm{L}$ phosphate buffer for 2 hours at $4^{\circ} \mathrm{C}$. Postfixation specimens were washed with distilled water and dehydrated through a graded ethanol series, substituted with propylene oxide, and embedded in epoxy resin. Ultrathin (80-nm-thick) sections were cut and stained with $2 \%$ uranyl acetate in $70 \%$ methanol for 4 minutes followed by Reynold's lead citrate for 3 minutes and observed with a JEOL 1200EX (JEOL, Tokyo, Japan) transmission electron microscope.

\section{Immunoblot Analysis}

Mouse intestinal mucosae were scraped from the small intestine, cecum, and colon and homogenized on ice in CelLytic MT (Sigma-Aldrich) and protease inhibitor cocktail (Sigma-Aldrich). The extracts were centrifuged at $20,000 \times g$ for 15 minutes at $4^{\circ} \mathrm{C}$, and the resulting supernatants were used for experiments. Equal amounts of total proteins were separated by SDS-PAGE under reducing conditions using $4 \%$ to $12 \%$ gradient gels and transferred onto an Immobilon membrane (Millipore, Bedford, MA). After blocking with $5 \%$ nonfat milk in Trisbuffered saline with $0.1 \%$ Tween 20 (TBS-T), the membranes were incubated overnight at $4^{\circ} \mathrm{C}$ with primary antibody, followed by washing with TBS-T and incubation with horseradish peroxidase-conjugated secondary antibody diluted in TBS-T with $1 \%$ bovine serum albumin for 1 hour at room temperature. The labeled proteins were visualized with a chemiluminescence reagent (PerkinElmer Life Science, Boston, MA).

\section{Statistical Analysis}

Comparison between two unpaired groups was made with repeated-measures analysis of variance or MannWhitney U-tests using SPSS 15.0 software (SPSS Japan Inc, Tokyo, Japan). Survival analysis was performed using Kaplan-Meyer survival curves, which were compared by the log-rank test using STAT view 5.0 (SAS Institute Inc., Cary, NC). The threshold for statistical significance was $P<0.05$.
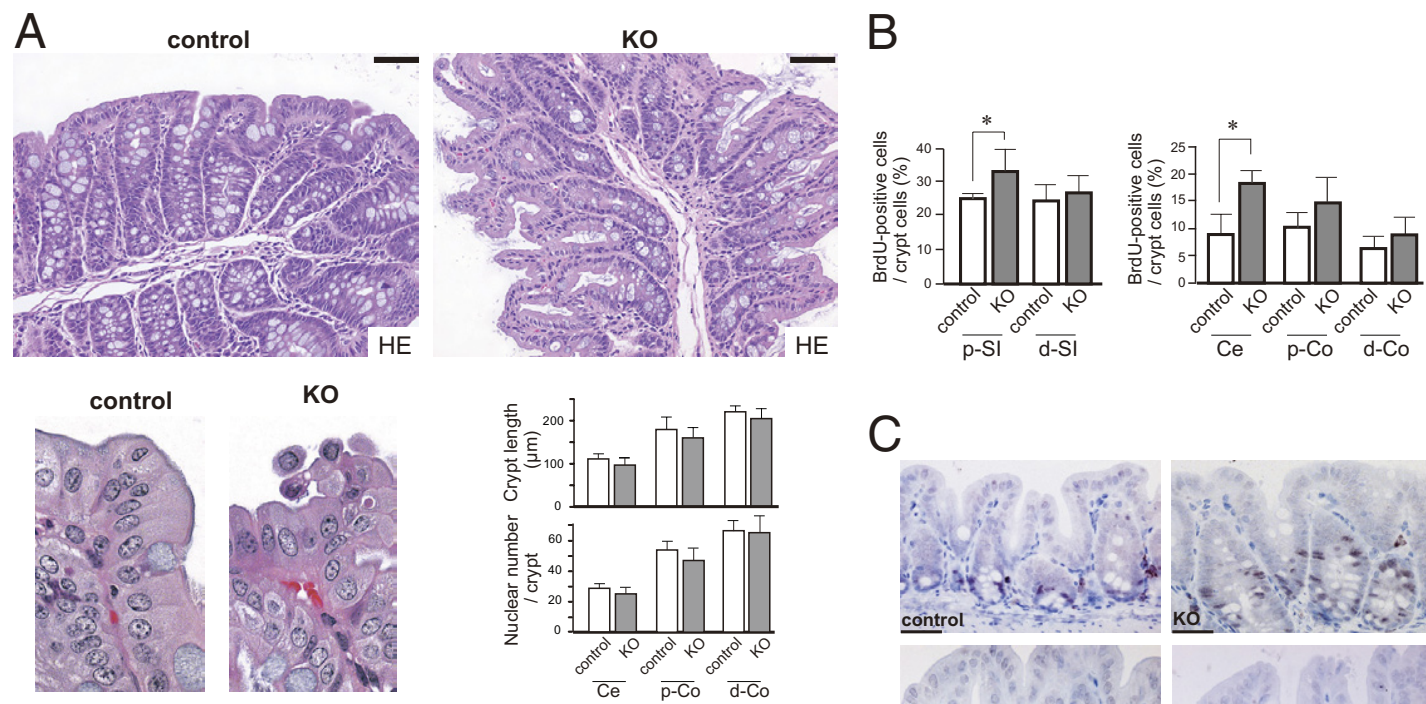

C
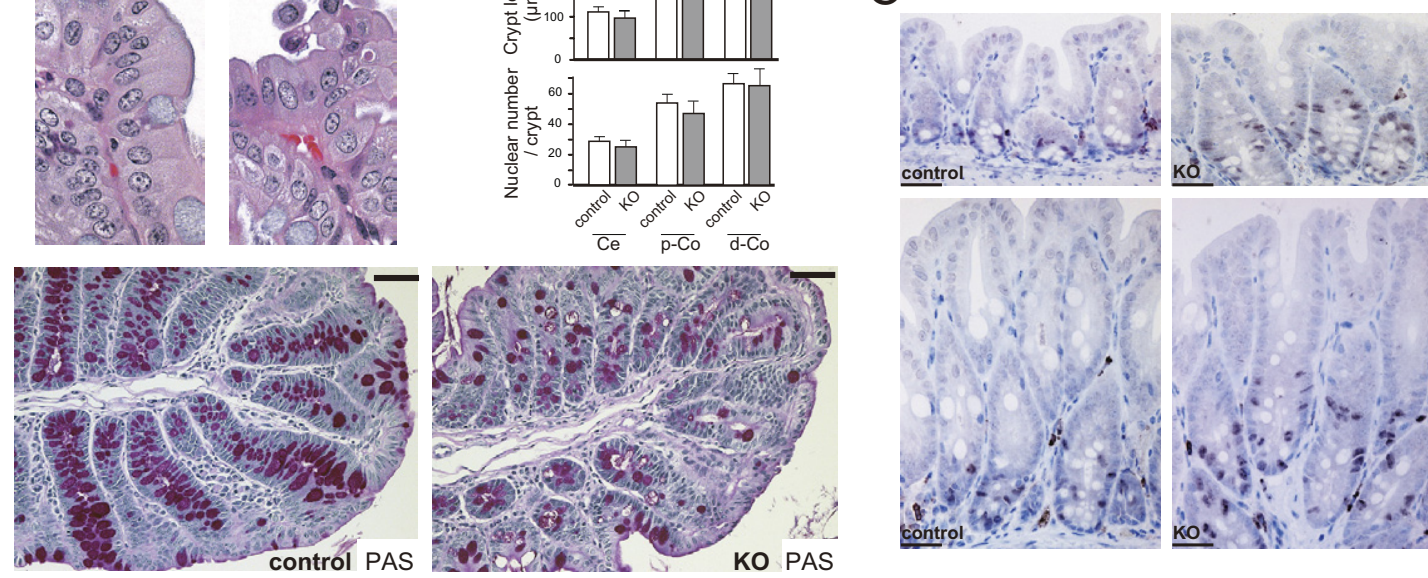

Figure 2. Histologic alterations of HAI-1/SPINT1-deficient intestinal epithelium. A: Histologic analysis (H\&E and PAS stains) of proximal aspect of the colon from littermate control Spint $1^{\text {LoxP/LoxP } / \text { Villin-Cre }}$ (control) and intestine-specific HAI-1/SPINT1-deficient Spint $1^{\text {LoxP/LoxP } / \text { Villin-Cre }}$ (/0 $(\mathrm{knockout)}$ mice. Scale bar $=50$ $\mu \mathrm{m}$. Higher-magnification photographs of the surface portion (H\&E) are also shown. Crypt length and total epithelial cell nuclei per each crypt of cecum (Ce), proximal aspect of the colon (p-Co), and distal aspect of the colon (d-Co) are shown. Ten crypts from each mouse were counted, and the values are the mean \pm SD of four mice. B: BrdU labeling index of intestinal segments from Spint $1^{\text {LoxP/LoxP } / \text { Villin-Cre }}{ }^{0}$ (control) and Spint $1^{\text {LoxP/LoxP } / \text { Villin-Cre }}{ }^{+/ 0}(\mathrm{knock}$ (kout) mice. Ten crypts from each mouse were counted, and the values are the mean $\pm \mathrm{SD}$ of four mice. p-SI, proximal small intestine; d-SI, distal small intestine. ${ }^{*} P<0.05$. C: Representative photos of BrdU immunohistochemistry (cecum). BrdU-positive cells are observed at the upper portion of the crypts from Spint1 LoxP/LoxP/Villin$\mathrm{Cre}^{+/ 0}$ (knockout) mice. Scale bar $=50 \mu \mathrm{m}$ 


\section{Results}

\section{Generation of Intestinal Epithelial Cell-Specific HAI-1/SPINT1-Null Mice}

To circumvent the embryonic lethality associated with $\mathrm{HAl}-1 /$ SPINT1 deficiency, we used the cre-loxP recombination system of bacteriophage $\mathrm{P} 1$ to achieve tissue-specific deletion of the Spint1 gene (Figure 1A). Intestinal epithelial cell-specific HAI-1/SPINT1-null mice were produced by crossing mice homozygous for Spint1 floxed alleles (Spint1 ${ }^{\text {LoxP/LoxP }}$ Nillin-Cre ${ }^{\mathrm{O}}$ ) with Villin-Cre transgenic mice having heterozygous floxed Spint1 (Spint $1^{\text {LoxP/+ }}$ Nillin$\mathrm{Cre}^{+/ 0}$ ) to generate Spint1 ${ }^{\text {LoxP/LoxP } / \text { Villin-Cre }}{ }^{+/ 0}$ (ie, intestine-specific HAI-1/SPINT1-deficient) mice and their associated Spint $1^{\text {LoxP/+}} /$ Villin-Cre ${ }^{+/ 0}$, Spint $1^{\text {LoxP/LoxP/ }}$ Villin-Cre ${ }^{0}$, and Spint $1^{\text {LoxP/+}} /$ Villin-Cre ${ }^{0}$ littermates. The intestinal tissue-specific defect of HAI-1/SPINT1 mRNA in spint1 ${ }^{\text {LoxP/LoxP/villin-Cre }}{ }^{+/ 0}$ was indicated by RT-PCR (Figure 1B) and real-time RT-PCR (Figure 1C) analyses. Subsequent immunohistochemical evaluation further confirmed the absence of the HAI-1/SPINT1 protein in intestinal epithelial cells of Spint $1_{\text {LoxP/LoxP/ }}$ Villin-Cre ${ }^{+/ 0}$ mice but not other epithelial tissues (Figure 1D). We also compared the expression of serine proteases, particularly those suggested to be HAI-1/ SPINT1 targets, in the intestinal tissues of intestinespecific HAI-1/SPINT1-deficient mice with their littermate controls. We detected no significant differences in the expression levels and patterns of the target proteases, such as HGFAC, matriptase, hepsin, prostasin, and TMPRSS13 (Figure 1E). HAI-2/SPINT2, a protein related to $\mathrm{HAI}-1 / \mathrm{SPINT} 1$ that also has a transmembrane domain and two extracellular Kunitz domains, is expressed abundantly throughout the intestinal tissues as well (Figure 1E). Apparent morphologic abnormalities could not be identified in the intestinespecific HAI-1/SPINT1-deficient mice by gross inspection, and growth retardation was not observed until 6 months after birth (data not shown). Intestinal symptoms, such as diarrhea and bloody stool, were not observed in the mutant mice.

\section{HAI-1/SPINT1 Deficiency Results in Histologic Abnormalities of Colonic Epithelium}

To query the possible function of HAI-1/SPINT1 in intestinal morphology, Spint $1^{\text {LoxP/LoxP } / \text { Nillin-Cre }}{ }^{+/ 0}$ mice were subjected for detailed morphologic analyses of the intestinal tissue. Macroscopically, the length of each small intestine and large intestinal segment (cecum, proximal half of colon, or distal half of colon) was the same for both Spint $1^{\text {LoxP/LOXP } / \text { Villin-Cre }}{ }^{+/ 0}$ and control littermate mice, and no visible abnormalities were apparent (data not shown). We next performed histologic examination of the intestinal tissues. Histologically, the large intestine of Spint ${ }^{\text {LoxP/LOXP } / \text { Villin-Cre }}{ }^{+/ 0}$ mice displayed varying degrees of crypt architecture dissolution compared with their littermate mice, with a tendency toward an increased number of shedding epithelial cells, which suggests increased apoptosis of surface epithelial cells (Figure $2 \mathrm{~A}$ ), with a mean number of shedding cells per one high-power field $(400 \times)$ of 3.8 and 0.1 for knockout $(n=$ 16) and control mice $(n=6)$, respectively, in the upper large intestine. These histologic abnormalities were more evident in the upper large intestine, particularly the cecum, compared with the distal large intestine. On the other hand, small intestine epithelium did not show notable histologic abnormalities after Spint1 gene deletion (data not shown). Crypt sizes may be modestly decreased in the HAl-1/SPINT1-deficient large intestine, but the differences were not statistically significant (Figure 2A). PAS staining revealed that the number of mucinfilled goblet cells was decreased (Figure 2A). The epithelial cells in the intestinal crypts showed increased mitotic activity as judged by BrdU labeling index (Figure 2B). The BrdUpositive cells were observed in upper portion of the $\mathrm{HAl}-1 /$ SPINT1-deficient crypts compared with the control crypts, indicating enhanced turnover of the epithelial cells in the absence of HAl-1/SPINT1 (Figure 2C).

To further evaluate the histologic abnormalities of HAI-1/ SPINT1-deficient intestine, we performed ultrastructural analysis of upper large intestine epithelium. As shown in Figure 3, the HAI-1/SPINT1-deficient colonic crypts showed a somewhat disorganized row of epithelial cells compared with control crypts, which had regularly ar-
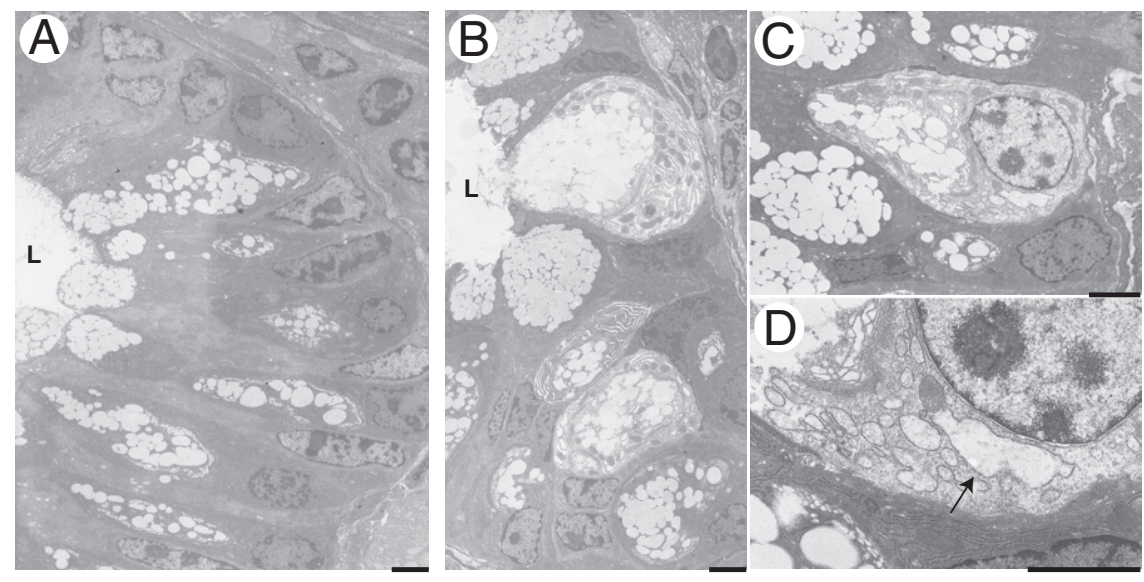

Figure 3. Transmission electron microscopy of the proximal aspect of the colon crypt epithelia from a littermate control Spint $1^{\text {LoxP/LoxP }} /$ Villin-Cre $e^{0}$ mouse (A) and a Spint $1^{\text {LoxP/LoxP }} /$ Villin-Cre $e^{+/ 0}$ mouse (B). L, crypt lumen. C and D: Higher-magnification photographs of epithelial cell with distended ER (arrow). Scale bar $=2 \mu \mathrm{m}$ 
ranged rows of epithelial cells. Notably, several goblet cells were expanded with low cytoplasmic electron density compared with control mice. In these cells, the endoplasmic reticulum (ER) was severely distended, which is a feature of ER stress (Figure 3D, arrow).

\section{Apoptosis Is Enhanced in HAl-1/SPINT1-Deficient Colonic Epithelium}

The morphologic analyses suggested that in the absence of HAI-1/SPINT1, crypt epithelial cells of the large intestine may show increased ER stress, apoptosis, and epithelial turnover. In fact, the number of cleaved caspase-3-positive cells was increased in Spint $1^{\text {LoxP/LoxP } / \text { Nillin-Cre }}{ }^{+/ 0}$ mice compared with their littermate controls, particularly in the upper large intestine (Figure 4, A and B). We could not analyze detailed subcellular relocalization of apoptosis-related molecules, such as Bcl-2, Bcl-xL, Bax, and Bad. However, at least, their mRNA levels were not altered significantly as determined by RT-PCR (Figure 4C) and real-time RT-PCR (data not shown). On the other hand, nuclear localization of phosphorylated JNK/SAPK was notably increased in the cecum and proximal aspect of the colon but not in the distal aspect of the colon (Figure 4D). Moreover, nuclear immunoreactivity of GADD153, a member of the C/EBP gene family of transcription factors that is up-regulated by ER stress, ${ }^{18}$ was also enhanced in HAI-1/SPINT1-deficient cecum and proximal aspect of the colon along with increased cleaved caspase-3 (Figure 4E). These observations may implicate the activation of ER stress-induced apoptotic pathway in the absence of HAI-1/SPINT1. In addition, we found that the
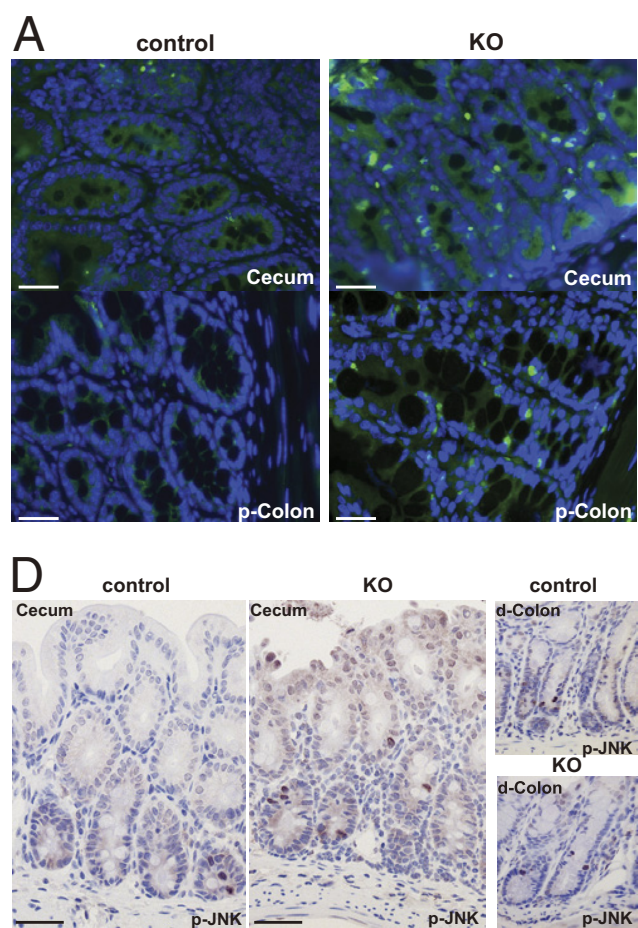
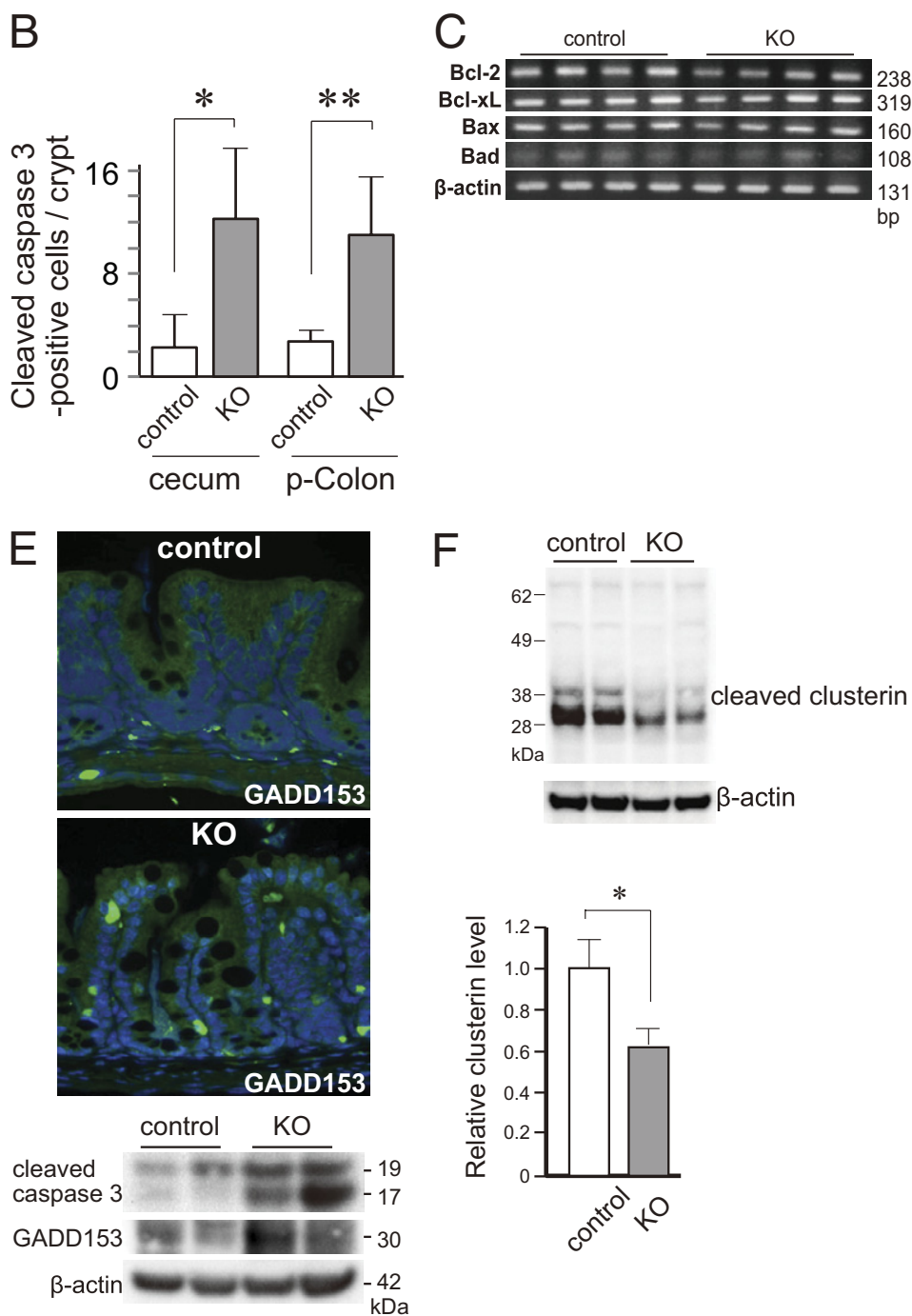

$\mathrm{F}$
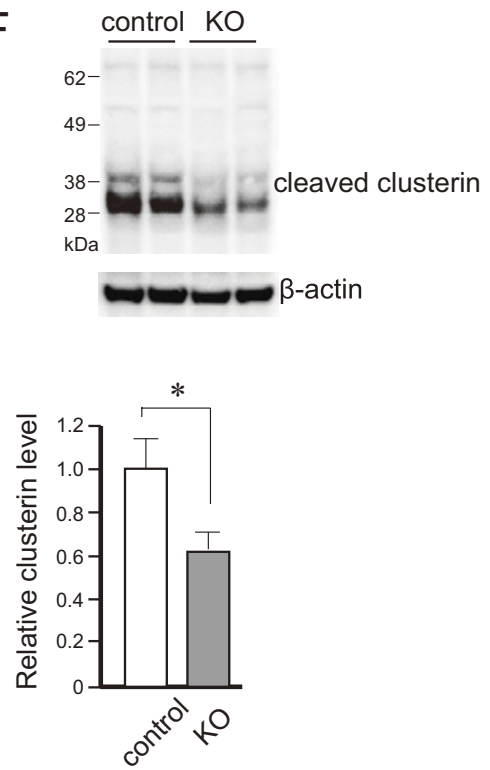

Figure 4. Enhanced apoptosis in HAI-1/SPINT1-deficient colon. A: Immunofluorescence analysis for cleaved caspase-3 in the cecum and proximal aspect of the colon (p-Colon) from Spint $1^{\text {LoxP/LoxP } / \text { Villin-Cre }}$ (control) or Spint $1^{\text {LoxP/LoxP }} /$ Villin-Cre ${ }^{+/ 0}$ (knockout) mice. B: Number of cleaved caspase-3 positive cells per crypt (mean + $\mathrm{SD}, n=4) .{ }^{*} P<0.005$; ${ }^{* *} P<0.001$. C: RT-PCR analysis for apoptosis-related molecules. D: Immunohistochemistry for phosphorylated JNK/SAPK in the cecum and distal aspect of the colon (d-Colon). Enhanced nuclear immunoreactivity was observed in HAI-1/SPINT1-deficient epithelial cells (knockout) compared with littermate controls

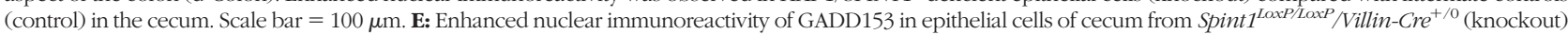
mice. Immunoblot analyses for cleaved caspase-3 and GADD153 using the same blot membrane are also shown. F: Decreased clusterin levels in proximal aspect of the colon mucosae from Spint $1^{\text {LoxP/LoxP } / \text { Villin-Cre }}{ }^{+/ 0}$ (knockout) mice relative to their littermate controls (control). Band intensity was normalized with respect to the intensity of the corresponding $\beta$-actin band, and the means \pm SD of four independent experiments are also shown. ${ }^{*} P<0.05$. 
A
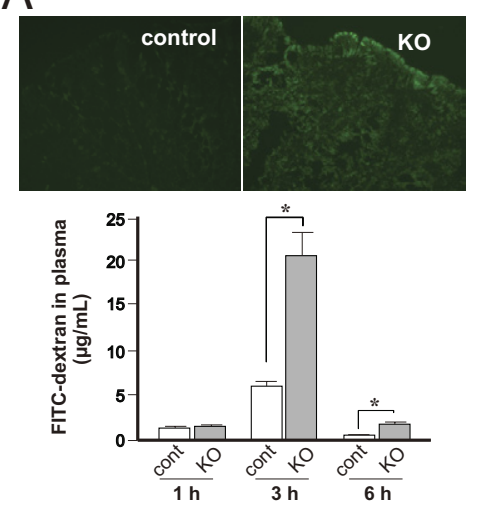

C

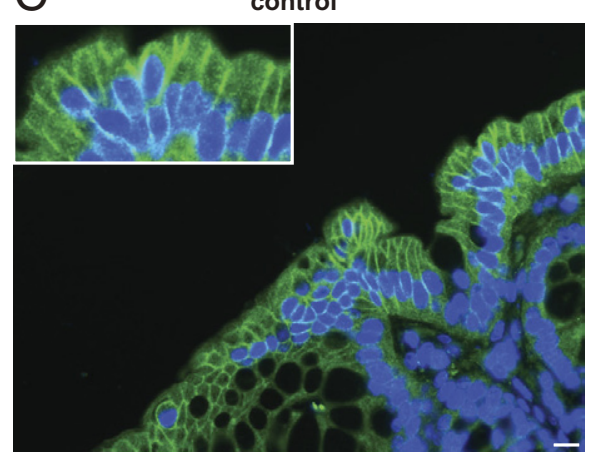

B

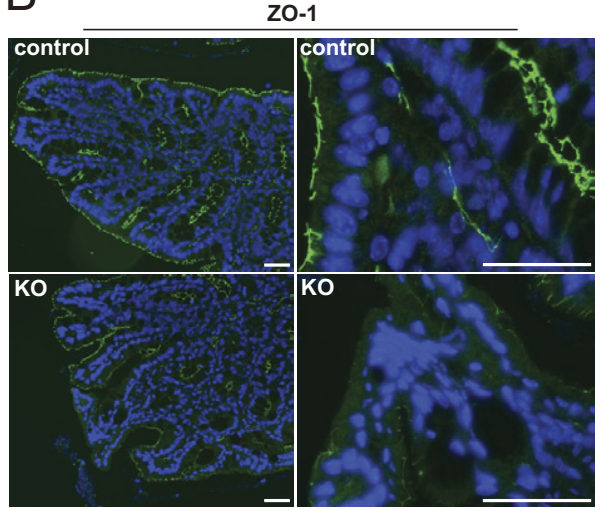

KO

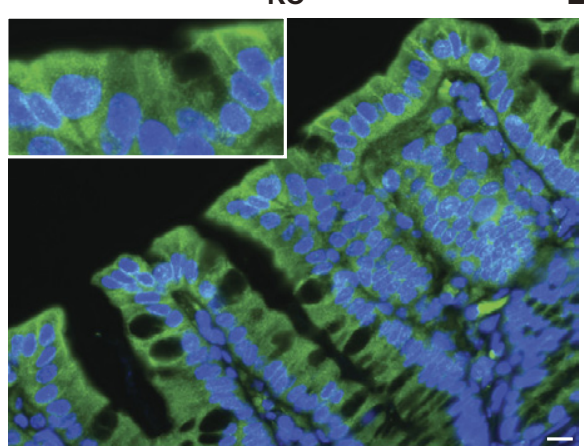

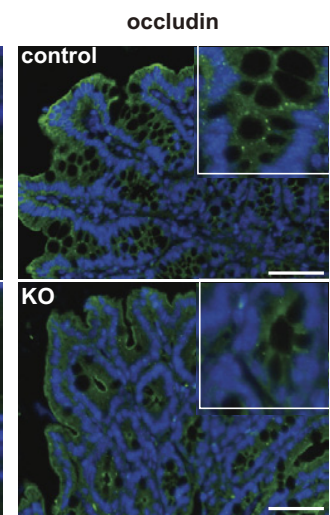

D control

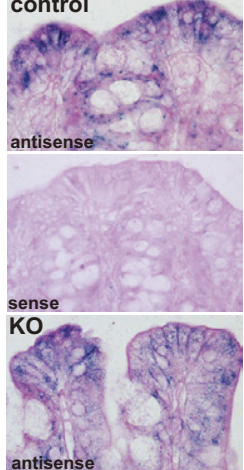

Figure 5. Enhanced permeability and deranged subcellular localization of matriptase in HAI-1/SPINT1-deficient upper large colon mucosa. A: Immunofluorescence of the mucosa (proximal aspect of the colon) from Spint $1^{\text {LoxP/LoxP } / \text { Villin-Cre }}{\text { (control) or Spint }{ }^{\text {LoxP/LoxP }} / \text { Villin-Cre }}^{+/ 0}$ (knockout) mice after administration of FITC-dextran by oral gavage. Plasma FITC-dextran levels were also measured 3 hours after administration, and indicated values are the means \pm SD of four independent experiments. ${ }^{*} P<0.05$. B: Altered expression patterns of ZO-1 and occludin observed in HAI-1/SPINT1-deficient proximal aspect of the colon mucosa showing abnormal histologic features. Higher magnification images are shown in the right panels (ZO-1) or insets (occludin). Knockout mouse epithelium shows foci absences. Scale bar $=50 \mu \mathrm{m}$. C: Subcellular localization of matriptase in proximal aspect of the colon epithelial cells. Scale bar $=20 \mu \mathrm{m}$. Higher magnification images are shown as insets. D: $I n$ situ hybridization for matriptase mRNA (proximal aspect of the colon). Control slide probed with sense RNA probe is also shown.

level of the secreted-form clusterin protein, an antiapoptotic and possibly cytoprotective molecule, ${ }^{19}$ was reduced in HAI-1/SPINT1-deficient intestinal tissue (Figure 4F).

\section{Intestinal Permeability Is Increased in the Absence of HAI-1/SPINT1}

Next we examined the mucosal permeability using FITCdextran. After oral administration of FITC-dextran, tissue fluorescence was easily detected in the upper large intestine of HAI-1/SPINT1-deficient mice but not in control mice, indicating enhanced permeability in the absence of HAI-1/SPINT1 (Figure 5A). Although this tracer permeates the intestinal barrier by paracellular diffusion, ${ }^{17}$ fluorescence was also observed within apical cells. However, the enhanced tissue fluorescence was not observed in the small intestine and was weak in the distal aspect of the colon (data not shown). Accordingly, plasma FITC-dextran levels were significantly increased in mutant mice (Figure 5A). Immunofluorescence analysis of the tight junction-associated proteins, ZO-1 and occludin, revealed irregular expression patterns in HAl-1/ SPINT1-deficient epithelium compared with control epithelium from upper large intestine and showed foci absences and/or decreased staining intensity (Figure
5B). Because these observations were similar to those reported for intestinal matriptase-deficient mice, ${ }^{17}$ we then examined the expression pattern of matriptase in the mucosa showing enhanced permeability. Interestingly, the basolateral surface localization of matriptase in colonic epithelial cells became oblique in the HAI-1/SPINT1-deficient cells, showing a rather diffuse cytoplasmic staining pattern (Figure 5C). This deranged matriptase immunolocalization pattern was observed in the crypt epithelia of the cecum and proximal aspect of the colon, which showed altered epithelial histologic architecture, but not in the small intestine and the other portions of large intestine with normal histologic architecture (data not shown). However, the cellular population responsible for matriptase mRNA expression was apparently unchanged as judged by in situ hybridization (Figure 5D).

\section{HAl-1/SPINT1 Deficiency Leads to Enhanced Susceptibility to DSS-Induced Experimental Colitis}

These results indicate that the absence of HAI-1/SPINT1 disrupts the epithelial integrity of the upper large intestine and may result in susceptibility to inflammatory injury. To test this hypothesis, we examined the effect of DSS- 

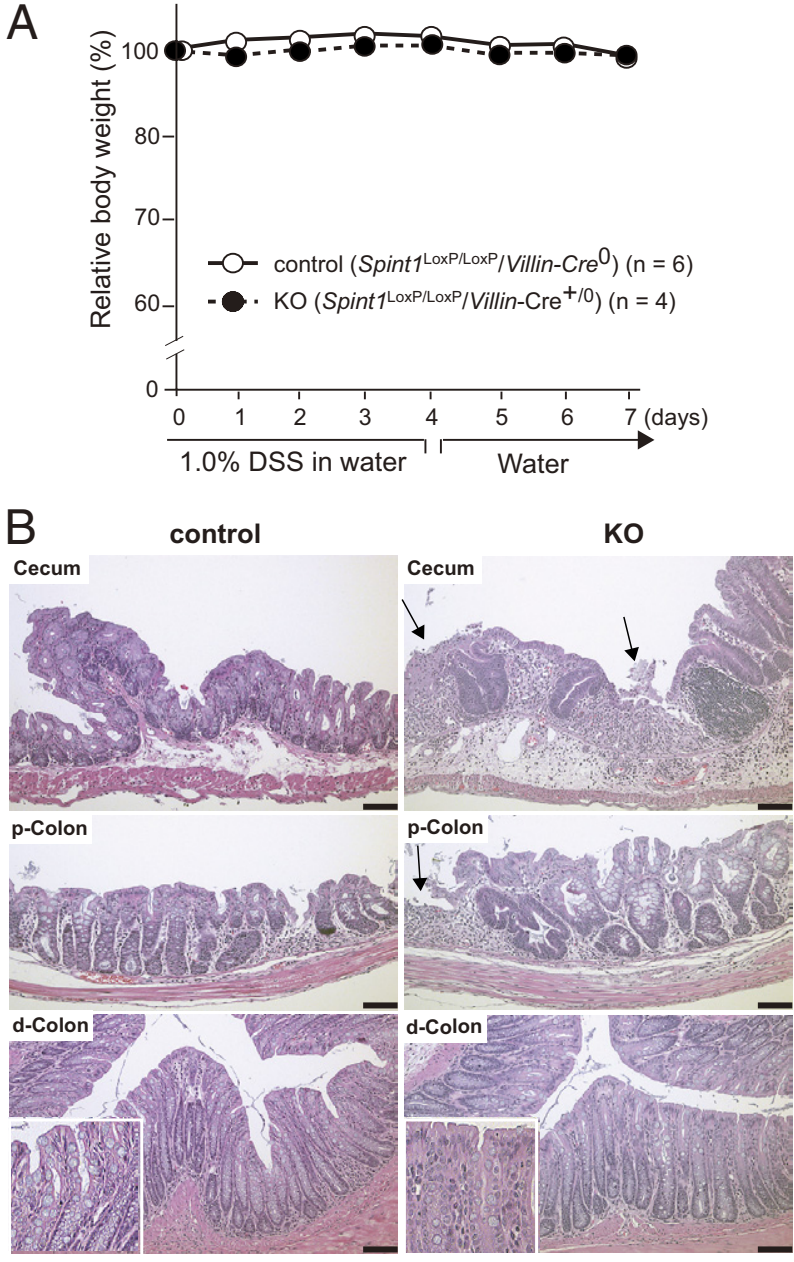

Figure 6. Effect of Spint1 deletion on mild DSS-induced mucosal injury (1\% DSS in drinking water for 4 days). A: Body weight changes for Spint $1^{\text {LoxP/LoxP }}$ Villin-Cre ${ }^{+/ 0}$ (knockout, $n=4$ ) mice and their littermate controls (control, $n=6$ ) under very mild DSS injury. B: Histologic analysis (H\&E) of the large intestine 7 days after stopping 1\% DSS treatment. Representative photographs for each large intestine segment from control and knockout mice are shown. Arrows indicate erosive lesions. p-Colon, proximal aspect of the colon; d-Colon, distal aspect of the colon. Scale bar $=100 \mu \mathrm{m}$. Insets Higher magnification of crypt epithelium from the distal aspect of the colon, showing depleted goblet cells in the absence of HAI-1/SPINT1.

induced intestinal injury, a mouse model of inflammatory bowel disease (IBD), ${ }^{20}$ on intestines of HAI-1/SPINT1deficient mice. With very mild DSS injury (1\% DSS in drinking water for 4 days), no significant differences of symptoms and body weight were observed between Spint $1^{\text {LOXP/LOXP } / \text { Villin-Cre }}{ }^{+/ 0}$ mice and their littermate controls (Figure 6A). However, even in this very mild injury model, there was a tendency for histologic mucosal regeneration to be delayed in the mutant mice. As shown in Figure 6B, mucosal erosion was occasionally observed in the HAI-1/SPINT1-deficient upper large intestine even 7 days after stopping DSS administration but not in control intestinal tissue. Although the persistent erosion was not observed in the distal aspect of the colon, the recovery of goblet cells was delayed in the HAI-1/SPINT1-deficient mice compared with control mice (Figure 6B). The differences became significant in the acute DSS colitis model (2.5\% DSS in drinking water for 7 days).
The Spint $1^{\text {LoxP/LoxP }} /$ Villin-Cre ${ }^{+/ 0}$ mice had more severe clinical symptoms as indicated by diarrhea, bloody stool, and weight loss and showed significantly lower survival ratios compared with control Spint $1^{\text {LoxP/LoxP }} /$ Villin-Cre ${ }^{0}$ mice (Figure 7A). Macroscopically, although the length of colon (proximal half of the colon and distal half of the colon) was equally shortened in both groups, the cecum length was significantly shorter in the intestinal HAl-1/ SPINT1-deficient mice compared with the controls (Figure 7B). Histologically, mucosal ulceration and shedding of epithelial cells were evident in HAI-1/SPINT1-deficient proximal aspect of the colon (Figure $7 \mathrm{C}$ ). The shedding HAI-1/SPINT1-deficient epithelial cells had vacuolated cytoplasm, and hobnail cells were occasionally observed also (Figure 7C, inset). The cecum mucosa of HAl-1/ SPINT1-deficient mice was totally ulcerated, whereas that of control mice was largely preserved (Figure 7D). Enhanced inflammatory activity in the HAI-1/SPINT1-deficient large intestine was also supported by increased mRNA levels of inflammatory cytokines, such as interleukin (IL)-1 $\beta$ and IL-6. The expression levels of Toll-like receptor (TLR)-2 and TLR-4 were not altered by the absence of $\mathrm{HAI}-1 / \mathrm{SPINT} 1$ (Figure 7E).

\section{Discussion}

The intestinal epithelium consists of specialized cell populations that undergo continuous and rapid renewal and is very vulnerable to injury from various exogenous and endogenous agents, including drugs, radiation, microorganisms, and unknown inflammatory processes called IBD. Proper regulation of epithelial architecture and cell survival is critical for maintaining mucosal barrier function and likely involves many factors. ${ }^{16}$ Recently, a trypsin-like transmembrane serine protease, matriptase, has emerged as an important molecule that is required for the homeostasis of multiple simple and stratified epithelia, including intestinal epithelium. ${ }^{17,21}$ This study provides evidence that the membrane-bound serine protease inhibitor HAI-1/SPINT1 is also required to maintain epithelial integrity in intestinal tissue. Indeed, matriptase is a well-known cognate protease of HAl-1/SPINT1, and the activity of matriptase is tightly regulated by this membrane-bound inhibitor. ${ }^{22}$

Mice lacking intestinal HAI-1/SPINT1 grew without significant weight loss, but showed mild histologic abnormalities in the upper large intestine and had a significantly enhanced susceptibility to DSS-induced mucosal injury. One unexpected outcome of this study is the differential effect of HAI-1/SPINT1 deficiency on the structural architecture and permeability of different intestinal segments. The histologic appearance of the small intestine was not altered, whereas that of the large intestine, particularly the cecum and proximal aspect of the colon, was changed and showed significantly increased permeability, although the reasons for these segmental differences are unclear. This phenotype shows a striking similarity to that observed for mice having an intestinespecific conditional deletion of the matriptase/St14 gene. ${ }^{17}$ Although the intestinal phenotype is more severe 
A
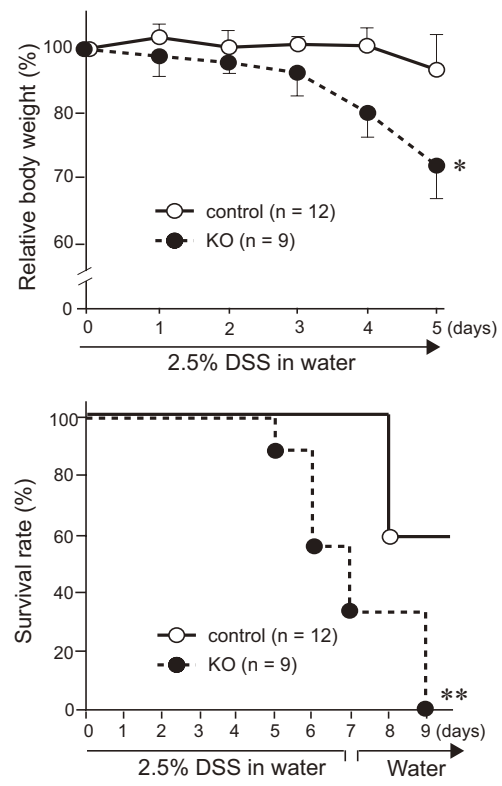

C

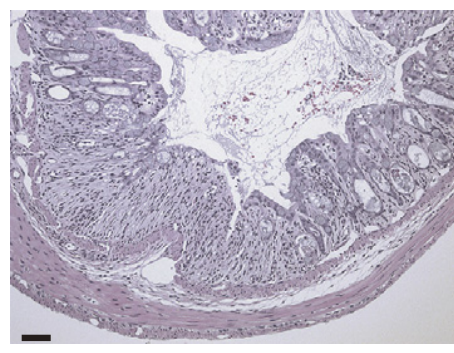

control

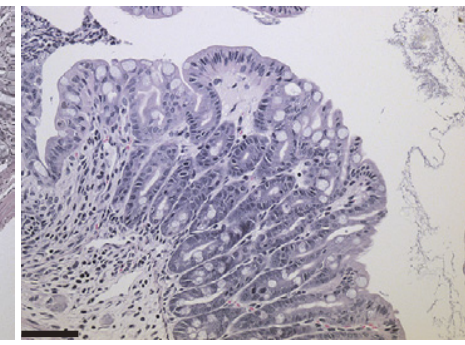

KO

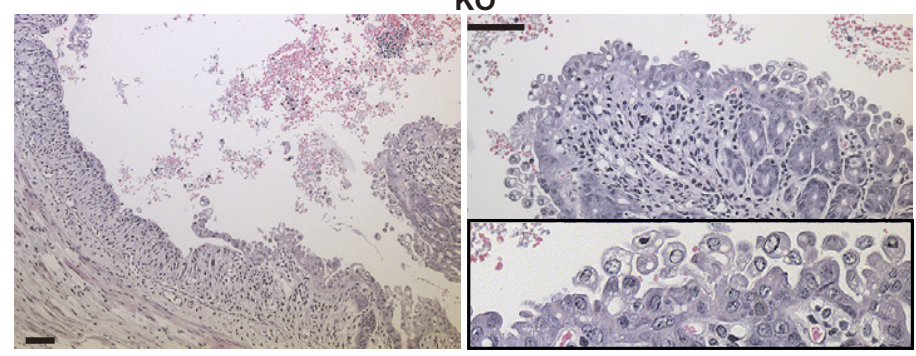

B

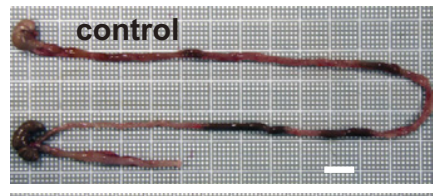

KO
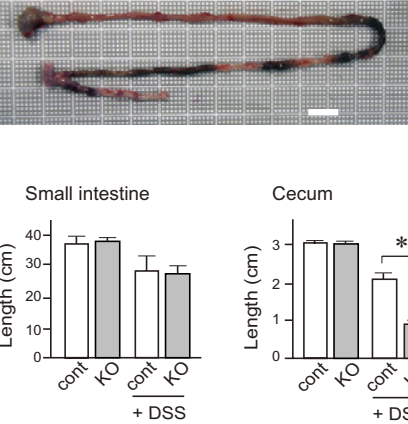

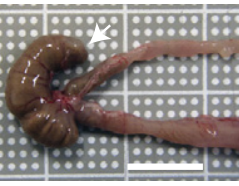

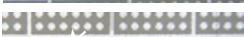
:

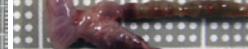
$:: \because::: \mid$ :andos:

D

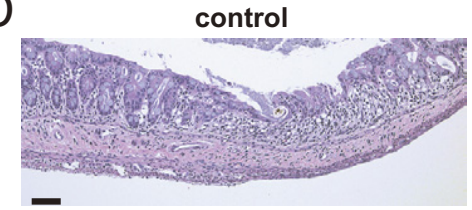

KO

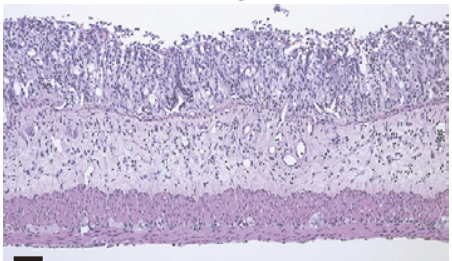

$E$

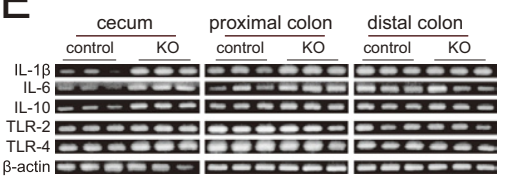

Figure 7. Effect of Spint1 deletion on severe DSS-induced mucosal injury (2.5\% in drinking water for 7 days). A: Body weight change and Kaplan-Meier survival curve for Spint $1^{\text {LoxP/LoxP } / \text { Villin-Cre }}{ }^{+/ 0}$ (knockout, $n=9$ ) mice and their littermate controls, Spint $1^{\text {LoxP } / \text { LoxP } / \text { Villin-Cre }}$ (control, $n=12$ ), under acute, severe DSS injury. The intestinal HAI-1/SPINT1-deficient mice showed significantly worse survival rates compared with their littermate controls. ${ }^{*} P<0.001 ; * * P<0.005$. B: Macroscopic appearance of intestinal tissues and comparison of segment length of intestines after severe DSS injury. Mice were sacrificed on day 7 of DSS treatment (2.5\% in drinking water). Arrows indicate the cecum. Scale bar $=10 \mathrm{~mm}$. Values in graphic figures are the means \pm SD $(n=5)$. ${ }^{*} P<0.01$. C: Histologic analysis of the proximal aspect of the colon on day 7 of DSS treatment. Representative photographs of damaged mucosa are shown in the left panel. Representative photographs of regenerative mucosa tissue near the ulcer edge are shown in the right panel. HAI-1/SPINT1-deficient mice showed more severe mucosal damage and enhanced shedding of the epithelial cells. High-power view of shedding epithelial cells is also shown (inset). Scale bar $=100 \mu \mathrm{m}$. D: Histologic analysis of the cecum on day 7 of DSS treatment. E: RT-PCR analysis of inflammatory cytokine (IL-1 $\beta$, IL-6, and IL-10) and TLR (TLR-2 and TLR-4) expression in each segment of large intestine on day 7 of DSS treatment.

for intestine-specific matriptase-deficient mice compared with the intestinal HAI-1/SPINT1-deficient mice described in this study, matriptase-deficient intestines also showed morphologic abnormalities in the large intestinal epithelium (but not the small intestine) and enhanced epithelial cell turnover and increased mucosal permeability. ${ }^{17}$ Therefore, the phenotypes observed in this study may be caused, at least in part, by deregulated matriptase activity due to the loss of HAI-1/SPINT1 as was previously observed for HAI-1/SPINT1-deficient placenta and skin. ${ }^{6-9}$ Recent studies suggested that HAl-1/ SPINT1 is responsible not only for the inhibition of matriptase activity but also for the proper intracellular trafficking and activation of matriptase in polarized human epithelial cells. ${ }^{22-26}$ We hypothesize that the maintenance of adequate matriptase activity at its proper subcellular localization might require $\mathrm{HAI}-1 / \mathrm{SPINT} 1$. The altered immunolocalization pattern of matriptase observed in the disorganized crypt epithelial cells of the HAI-1/SPINT1deficient colon may support this hypothesis. In the ab- 
sence of HAI-1/SPINT1, epithelial cells may be unable to use matriptase properly to maintain the epithelial integrity. Notably, apoptotic cells were increased in the HAl1/SPINT1-deficient epithelium of the upper large intestine, in which markedly distended ERs were also observed ultrastructurally. The underlying mechanism for ER stress in these cells is currently unknown, but this ER stress may be responsible for the enhanced apoptosis that was observed. ${ }^{27}$ In fact, nuclear immunoreactivities of GADD153 and phosphorylated JNK/SAPK, both of which are up-regulated in the ER stress-induced apoptosis pathway, ${ }^{18}$ were enhanced in HAl-1/SPINT1-deficient crypt epithelium. In addition, secreted clusterin was decreased in the HAI-1/SPINT1-deficient mucosa. Although the biological functions of clusterin remain unclear, recent studies suggested that it has roles in response to cellular stress, antiapoptosis, and cellular survival. ${ }^{19}$

The intestinal epithelial cells also express another membrane-bound Kunitz-type serine protease inhibitor, namely HAI-2/SPINT2 (also known as placental bikunin). ${ }^{28-30} \mathrm{HAl}-2 /$ SPINT2 shows similar molecular structure to HAI-1/SPINT1 but lacks the low-density lipoprotein receptor-like domain and $\mathrm{N}$-terminal cysteine-rich domain and has an overlapping inhibitory spectrum. ${ }^{2,28}$ In fact, analysis using a mutant mouse model revealed that HAI-2/SPINT2 also regulates matriptase activity in vivo. ${ }^{31}$ Therefore, it is possible that in this conditional knockout study HAI-2/SPINT2 compensated for the absence of HAI1/SPINT1, particularly in the small intestine and/or distal aspect of the colon. Notably, a recent study revealed that mutation of the SPINT2 gene results in a syndromic form of congenital sodium diarrhea, which also indicates a significant role for this membrane-bound serine protease inhibitor in the intestinal epithelial function. ${ }^{32}$

The important role of HAI-1/SPINT1 in the colonic mucosa was also shown in a model for mucosal injury that involves DSS administration. In this model, DSS seems to be directly toxic to colonic epithelial cells of the basal crypts and affects the integrity of the mucosal barrier, and this mouse colitis model is widely used for the study of human IBD. ${ }^{20}$ Our study confirmed that mice lacking intestinal HAI-1/SPINT1 are much more susceptible to DSS-induced mucosal injury (2.5\% DSS in drinking water for 7 days) with a high mortality ratio and delayed mucosal regeneration even after very low-dose DSS treatment (1\% DSS in drinking water for 4 days). This observation may be in accordance with a previous study that revealed that regenerating intestinal epithelial cells show enhanced expression of HAI-1/SPINT1 but not HAI-2/ SPINT2. ${ }^{33}$ Regarding the mechanism underlying these observations, matriptase hypomorphic mice are also susceptible to DSS colitis, again suggesting important roles for optimal matriptase activity in intestinal epithelial homeostasis and integrity. ${ }^{21}$ However, expression of claudin-2, a leaky claudin that was up-regulated in the intestine of matriptase hypomorhic mice, ${ }^{21}$ was not apparently enhanced in Hai-1/Spint1-deficient intestine (data not shown). Altered pericellular activation of HGF, which can be activated by matriptase or HGFAC, ${ }^{10,34}$ may be involved in these phenotypes, which should be tested in a future study. The specific receptor of HGF (ie, c-Met) is expressed by intestinal epithelial cells, and HGF/c-Met signaling has an important role in mucosal regeneration. ${ }^{35}$ Previous studies suggested that HAI-1/SPINT1 is responsible for regulating the optimal activity not only of matriptase but also of pericellular HGFAC because this membrane-bound inhibitor inhibits and retains activated HGFAC on the cell surface in a reversible fashion and releases it in response to inflammatory stimuli. ${ }^{10,36} \mathrm{In}$ deed, Hgfac knockout mice also showed enhanced susceptibility to DSS-induced colitis, possibly due to insufficient activation of HGF after acute mucosal injury. ${ }^{37}$ Interestingly, a recent gene-centric mapping analysis suggests that the MST1 gene encoding MSP, which is another cytokine activated by HGFAC and matriptase, ${ }^{38,39}$ may be involved in IBD pathogenesis. ${ }^{40}$ Therefore, altered pericellular activation of MSP may also be involved in the susceptibility of HAI-1/SPINT1-deficient mice to DSS colitis.

In summary, we developed a conditional knockout model of HAl-1/SPINT1 to study the tissue-specific function of HAI-1/SPINT1 in vivo. This study revealed a crucial role for HAI-1/SPINT1 in maintaining the integrity of coIonic epithelium, and dysfunction of this inhibitor likely enhances susceptibility to mucosal injury. Therefore, it will be of interest to determine whether genetic polymorphisms affecting HAI-1/SPINT1 abundance or activity contribute to susceptibility to IBDs, such as Crohn's disease and ulcerative colitis. The model described here will provide an important animal model for the future study of HAI-1/SPINT1 and its target proteases in intestinal disease.

\section{Acknowledgments}

We thank Drs. Hiroshi Orikawa, Yukihiro Haruyama, and Kazuyo Kohama and Ms. Yasuko Tobayashi for their valuable suggestions and excellent technical assistance.

\section{References}

1. Shimomura T, Denda K, Kitamura A, Kawaguchi T, Kito M, Kondo J, Kagaya S, Qin L, Takata H, Miyazawa K, Kitamura N: Hepatocyte growth factor activator inhibitor, a novel Kunitz-type serine protease inhibitor. J Biol Chem 1997, 272:6370-6376

2. Kataoka H, Miyata S, Uchinokura S, Itoh $\mathrm{H}$ : Roles of hepatocyte growth factor (HGF) activator and HGF activator inhibitor in the pericellular activation of HGF/scatter factor. Cancer Metastasis Rev 2003, 22:223-236

3. Itoh H, Yamauchi M, Kataoka H, Hamasuna R, Kitamura N, Koono M: Genomic structure and chromosomal localization of the human hepatocyte growth factor activator inhibitor type 1 and 2 genes. Eur J Biochem 2000, 267:3351-3359

4. Kataoka $H$, Suganuma $T$, Shimomura $T$, Itoh $H$, Kitamura N, Nabeshima K, Koono M: Distribution of hepatocyte growth factor activator inhibitor type 1 (HAl-1) in human tissues: cellular surface localization of $\mathrm{HAl}-1$ in simple columnar epithelium and its modulated expression in injured and regenerative tissues. J Histochem Cytochem 1999, 47:673-682

5. Kataoka H, Meng JY, Itoh H, Hamasuna R, Shimomura T, Suganuma $\mathrm{T}$, Koono M: Localization of hepatocyte growth factor activator inhibitor type 1 in Langhans' cells of human placenta. Histochem Cell Biol 2000, 114:469-475

6. Tanaka H, Nagaike K, Takeda N, Itoh H, Kohama K, Fukushima T, Miyata S, Uchiyama S, Uchinokura S, Shimomura T, Miyazawa K, Kitamura N, Yamada G, Kataoka H: Hepatocyte growth factor activa- 
tor inhibitor type 1 (HAl-1) is required for branching morphogenesis in the chorioallantoic placenta. Mol Cell Biol 2005, 25:5687-5698

7. Szabo R, Molinolo A, List K, Bugge TH: Matriptase inhibition by hepatocyte growth factor activator inhibitor- 1 is essential for placental development. Oncogene 2007, 26:1546-1556

8. Nagaike K, Kawaguchi M, Takeda N, Fukushima T, Sawaguchi A, Kohama K, Setoyama M, Kataoka H: Defect of hepatocyte growth factor activator inhibitor type 1/serine protease inhibitor. Kunitz type 1 (HAI-1/SPINT1) leads to ichthyosis-like condition and abnormal hair development in mice. Am J Pathol 2008, 173:1464-1475

9. Szabo R, Kosa P, List K, Bugge TH: Loss of matriptase suppression underlies spint1 mutation-associated ichthyosis and postnatal lethality. Am J Pathol 2009, 174:2015-2022

10. Kataoka H, Kawaguchi M: Hepatocyte growth factor activator (HGFA): pathophysiological functions in vivo. FEBS J 2010, 277: 2230-2237

11. Hashimoto T, Kato M, Shimomura T, Kitamura N: TMPRSS13, a type II transmembrane serine protease, is inhibited by hepatocyte growth factor activator inhibitor type 1 and activates pro-hepatocyte growth factor. FEBS J 2010, 277:4888-4900

12. Bugge TH, Antalis TM, Wu Q: Type II transmembrane serine proteases. J Biol Chem 2009, 284:23177-23181

13. Carney TJ, von der Hardt S, Sonntag C, Amsterdam A, Topczewski J, Hopkins N, Hammerschmidt M: Inactivation of serine protease Matriptase 1a by its inhibitor Hai1 is required for epithelial integrity of the zebrafish epidermis. Development 2007, 134:3461-3471

14. Cheng H, Fukushima T, Takahashi N, Tanaka H, Kataoka H: Hepatocyte growth factor activator inhibitor type 1 regulates epithelial to mesenchymal transition through membrane-bound serine proteinases. Cancer Res 2009, 69:1828-1835

15. Fukushima T, Kawaguchi M, Yamasaki M, Tanaka H, Yorita $\mathrm{K}$, Kataoka H: Hepatocyte growth factor activator inhibitor type 1 suppresses metastatic pulmonary colonization of pancreatic carcinoma cells. Cancer Sci 2011, 102:407-413

16. Turner JR: Intestinal mucosal barrier function in health and disease. Nat Rev Immunol 2009, 9:799-809

17. List K, Kosa P, Szabo R, Bey AL, Wang CB, Molinolo A, Bugge TH: Epithelial integrity is maintained by a matriptase-dependent proteoIytic pathway. Am J Pathol 2009, 175:1453-1463

18. Kim R, Emi M, Tanabe K, Murakami S: Role of the unfolded protein response in cell death. Apoptosis 2003, 11:5-13

19. Zoubeidi A, Chi K, Gleave M: Targeting the cytoprotective chaperone, clusterin, for treatment of advanced cancer. Clin Cancer Res, 2010, 16:1088-1093

20. Wirts S, Neufert C, Weigmann B, Neurath MF: Chemically induced mouse models of intestinal inflammation. Nat Protoc 2007, 2:541-546

21. Buzza MS, Netzel-Arnett S, Shea-Donohue T, Zhao A, Lin CY, List K, Szabo R, Fasano A, Bugge TH, Antalis TM: Membrane-anchored serine protease matriptase regulates epithelial barrier formation and permeability in the intestine. Proc Natl Acad Sci U S A 2010, 107: 4200-4205

22. List K, Bugge TH, Szabo R: Matriptase: potent proteolysis on the cell surface. Mol Med 2006, 12:1-7

23. Oberst MD, Williams CA, Dickson RB, Johnson MD, Lin CY: The activation of matriptase requires its noncatalytic domains, serine protease domain, and its cognate inhibitor. J Biol Chem 2003, 278: 26773-26779

24. Oberst MD, Chen LY, Kiyomiya K, Williams CA, Lee MS, Johnson MD, Dickson RB, Lin CY: HAl-1 regulates activation and expression of matriptase, a membrane-bound serine protease. Am J Physiol Cell Physiol 2005, 289:C462-470

25. Godiksen S, Selzer-Plon J, Pedersen ED, Abell K, Rasmussen HB, Szabo R, Bugge TH, Vogel LK: Hepatocyte growth factor activator inhibitor-1 has a complex subcellular itinerary. Biochem J 2008, 413: $251-259$
26. Miyake Y, Tsuzuki S, Yasumoto M, Fushiki T, Inouye K: Requirement of the activity of hepatocyte growth factor activator inhibitor type 1 for the extracellular appearance of a transmembrane serine protease matriptase in monkey kidney COS-1 cells. Cytotechnology 2009, 60:95-103

27. Tabas I, Ron D: Integrating the mechanisms of apoptosis induced by endoplasmic reticulum stress. Nat Cell Biol 2011, 13:184-190

28. Kawaguchi T, Qin L, Shimomura T, Kondo J, Matsumoto K, Denda K, Kitamura N: Purification and cloning of hepatocyte growth factor activator inhibitor type 2, a Kunitz-type serine protease inhibitor. J Bio Chem 1997, 272:27558-27564

29. Marlor CW, Delaria KA, Davis G, Muller DK, Greve JM, Tamburini PP: Identification and cloning of human placental bikunin, a novel serine protease inhibitor containing two Kunitz domains. J Biol Chem 1997, 272:12202-12208

30. Kataoka $\mathrm{H}$, Itoh $\mathrm{H}$, Uchino $\mathrm{H}$, Hamasuna R, Kitamura N, Nabeshima $\mathrm{K}$, Koono $\mathrm{M}$ : Conserved expression of hepatocyte growth factor activator inhibitor type-2/placental bikunin in human colorectal carcinomas. Cancer Lett 2000, 148:127-134

31. Szabo R, Hobson JP, Christoph K, Kosa P, List K, Bugge TH: Regulation of cell surface protease matriptase by HAI2 is essential for placental development, neural tube closure and embryonic survival in mice. Development 2009, 136:2653-2663

32. Heinz-Erian P, Muller T, Krabichler B, Schranz M, Becker C, Ruschendorf F, Nurnberg P, Rossier B, Vujic M, Booth IW, Holmberg C, Wijmenga C, Grigelioniene G, Kneepkens CM, Rosipal S, Mistrik M, Kappler M, Michaud L, Doczy LC, Siu VM, Krantz M, Zoller H, Utermann G, Janecke AR: Mutations in SPINT2 cause a syndromic form of congenital sodium diarrhea. Am J Hum Genet 2009, 84:188-196

33. Itoh $\mathrm{H}$, Kataoka $\mathrm{H}$, Tomita M, Hamasuna $\mathrm{R}$, Nawa $\mathrm{Y}$, Kitamura $\mathrm{N}$, Koono M: Upregulation of HGF activator inhibitor type 1 but not type 2 along with regeneration of intestinal mucosa. Am J Physiol Gastrointest Liver Physiol 2000, 278:G635-G643

34. Owen KA, Qiu D, Alves J, Schumacher AM, Kilpatrick LM, Li J, Harris $\mathrm{JL}$, Ellis V: Pericellular activation of hepatocyte growth factor by the transmembrane serine proteases matriptase and hepsin, but not by the membrane-associated protease uPA. Biochem J 2010, 426:219-228

35. Nakamura T, Sakai K, Nakamura T, Matsumoto K: Hepatocyte growth factor twenty years on: much more than a growth factor. J Gastroenterol Hepatol 2011, 26(Suppl 1):188-202

36. Kataoka H, Shimomura $T$, Kawaguchi $T$, Hamasuna R, Itoh H, Kitamura N, Miyazawa K, Koono M: Hepatocyte growth factor activator inhibitor type 1 is a specific cell surface binding protein of hepatocyte growth factor activator (HGFA) and regulates HGFA activity in the pericellular microenvironment. J Biol Chem 2000, 275:40453-40462

37. Itoh H, Naganuma S, Takeda N, Miyata S, Uchinokura S, Fukushima T, Uchiyama S, Tanaka H, Nagaike K, Shimomura T, Miyazawa K, Yamada G, Kitamura N, Koono M, Kataoka H: Regeneration of injured intestinal mucosa is impaired in hepatocyte growth factor activatordeficient mice. Gastroenterology 2004, 127:1423-1435

38. Kawaguchi M, Orikawa H, Baba T, Fukushima T, Kataoka H: Hepatocyte growth factor activator is a serum activator of single-chain precursor macrophage-stimulating protein. FEBS J 2009, 276:34813490

39. Bhatt AS, Welm A, Farady CJ, Vasquez M, Wilson K, Craik CS Coordinate expression and functional profiling identify an extracellular proteolytic signaling pathway. Proc Natl Acad Sci U S A 2007, 104:5771-5776

40. Goyette P, Lefebvre C, Ng A, Brant SR, Cho JH, Duerr RH, Silverberg MS, Taylor KD, Latiano A, Aumais G, Deslandres C, Jobin G, Annese V, Daly MJ, Xavier RJ, Rioux JD: Gene-centric association mapping of chromosome 3p implicates MST1 in IBD pathogenesis. Mucosal Immunol 2008, 1:131-138 